\title{
Experiences of Pre-School Teacher Candidates on the Development and Application of Slowmation in Science Education
}

\author{
Zehra Özdilek $^{1} \&$ Betül Ugur ${ }^{2}$ \\ ${ }^{1}$ Faculty of Education, Bursa Uludag University, Bursa, Turkey \\ ${ }^{2}$ Institute of Educational Sciences, Bursa Uludag University, Bursa, Turkey \\ Correspondence: Zehra Özdilek, Faculty of Education, Mathematics and Science Education Department, Bursa \\ Uludag University, Görükle, Bursa, Turkey. E-mail: zozdilek@uludag.edu.tr
}

Received: June 14, 2019

Accepted: July 31, 2019 Online Published: September 20, 2019

doi:10.5539/jel.v8n5p152

URL: https://doi.org/10.5539/jel.v8n5p152

\begin{abstract}
The purpose of the study is to examine the pre-school teacher candidates' experiences in developing and using a Slowmation as an educational technique with young children. This study also aims at providing the pre-school teachers' reflections on the whole development and application process. The study was carried out with 65 pre-school teacher candidates ( 46 of them are from day classes and 19 of them are from evening classes) who were studying in the pre-school education department in the spring term of the 2017-2018 academic year. The researcher used phenomenological research method which relied on these data resources: field notes, open-ended questions, videos and photos and semi-structured interviews. It was concluded that pre-school teacher candidates have developed their skills in using the Slowmation technique during the course. The researchers also concluded that the Slowmation technique, despite having some limitations, has a positive effect on pre-school students' learning process of the science concepts and it could contribute significantly to their skill development process.
\end{abstract}

Keywords: science education, Slowmation, pre-service preschool teacher candidates, qualitative research

\section{Introduction}

\subsection{Introduce the Problem}

Developments in science and technology have reflected in educational sciences and integrated into many learning approaches. Over the past two decades, the integration of computer technology into classroom teaching and learning has become an inevitable part of many new educational reforms at the K-12 level (Lin, 2012). Learning environments created in accordance with the technological dimension in education are generally student-centered. In these environments, teachers play a guiding role, while students are more active in their learning process.

Digital competence, which is one of the eight core competencies emphasized in Turkish Science Education Program (Primary and Secondary School); identifies access to information and use of computers in the evaluation, production, transfer and exchange of information (Turkish Ministry of National Education, 2018). In this context, it is crucial to introduce technology enhanced teaching and learning methods to teacher candidates in the current practices (Hoban, 2005). The Slowmation technique, which is very popular in the recent use of computers in education, has been used as one of the methods that encourages students to be active in science education (Brown, Murcia, \& Hackling, 2013) and to improve technology literacy (Paige, Bentley, \& Dobson, 2016).

\subsection{Theoretical Framework}

Slowmation (abbreviated from slow and animation) is a simplified method for students to perform a stop-and-start animation as an innovative way to represent and explain a science concept (Hoban, 2007). Students can use their own digital cameras and computers and free movie making software to design animations (Hoban \& Nielsen, 2010). Slowmation technique uses easy-to-find materials such as models, play doughs, real-life objects and is played at two frames per second to produce "slow animations" by also integrating digital storytelling (Hoban \& Nielsen, 2010; Hoban \& Nielsen, 2013; Keast et al., 2010). Therefore, the slow speed of animations facilitates understanding of the scientific concept (Hoban, Loughran, \& Nielsen, 2011; Kervin, 2007). 
When the related studies were examined, it seems that the Slowmation technique has many advantages and therefore could become one of the most prominent applications in primary and secondary schools (Paige, Bentley, \& Dobson, 2016). Students transfer their knowledge about science concepts in the process of preparing their animations, which requires teamwork (Hoban, Macdonald, Ferry, \& Hoban, 2009). In this way, communication skills are developed through collaboration within the group. Using technology in a popular setting, especially in digital animation, is an effective way for teacher candidates to interact with learning the content of scientific knowledge (Macdonald \& Hoban, 2009).

Related studies showed that the implementations are generally carried out with teacher candidates (Hoban, 2007; Hoban \& Nielsen, 2012; Hoban \& Nielsen, 2013; Hoban \& Nielsen, 2014; Hoban et al., 2011; Macdonald \& Hoban, 2009; Nielsen \& Hoban, 2015; Paige et al., 2016). There are also studies in the literature, especially with children in small classes (Hoban \& Nielsen, 2010; Kervin, 2007). It is obvious that using the Slowmation technique is an innovative way of doing deliberate instruction in early childhood settings as young children create digital animations about science concepts (Fleer \& Hoban, 2012). Students who prepare Slowmations are more capable of explaining the science concepts they have learned (Hoban et al., 2011).

\subsection{Preschool Education Program of Turkey}

Preschool education prepares children for the daily life. In this period of rapid growth, children tend to discover everything with curiosity. The formation of many concepts that will come up later in their lives is laid in this period. In Turkey, preschool education program is a developmental program in which the social and emotional, motor, cognitive and language development characteristics and self-care skills of the child are handled together with a holistic approach (MoNE, 2013). The program includes the gains, indicators and explanations related to the areas of development.

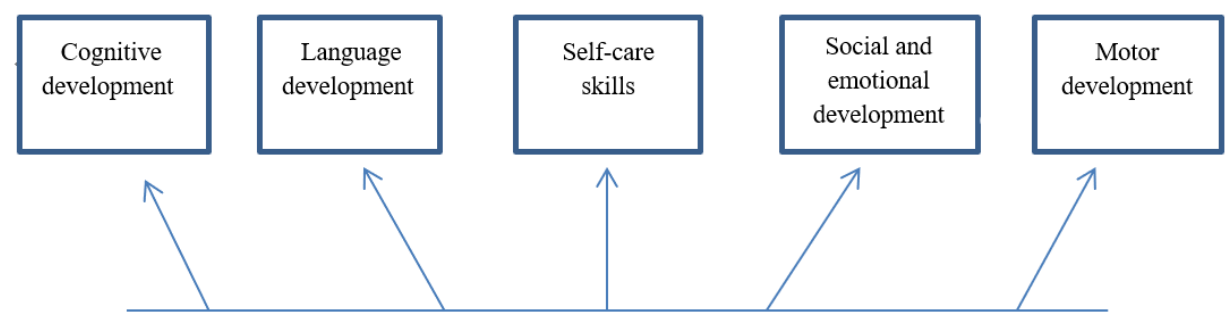

Figure 1. Development areas in preschool education

It is necessary to reach the highest level in motor, emotional and social, language and cognitive development in order to ensure the healthy growth of preschool children by gaining rich learning experiences. Some of the basic features of the pre-school education program are (MoNE, 2013);

- Child-centered: Teachers need to encourage active participation in the learning process in order to develop a positive attitude towards children's research, questioning, discussion, production and learning.

- Flexible: The preschool education program is suitable for adapting to the changing characteristics of the child, physical environment and family.

- Eclectic: It is a synthesis program created by using child-centered practices in different learning theories to meet the needs of the 21st century and to meet the national characteristics and requirements.

- Balanced: As the development of children needs to be supported in many ways, the gains and indicators in all development areas should be balanced in the program.

- Game-based: The game is the child's language. Learning through play is an integral part of preschool education.

- Learning through discovery: The preschool education program encourages the child to recognize, research, question and discover what is happening around him for meaningful learning.

- Development of creativity is in the forefront: In the learning process, different materials, methods and techniques should be created for children to create an environment suitable for their individual 
differences and learning needs and to provide opportunities for them to express themselves in a unique way.

- Encourages the use of daily life experiences and close environment opportunities for educational purposes: The use of daily life experiences and close environment opportunities both enriches and facilitates the education process.

- Themes/topics are not tools but objectives: In this process, it is aimed to achieve gains and indicators with the help of the subject, not teaching the subject.

- Learning centers are important: In these centers, children can freely demonstrate their skills and experience. Centers can be indoor environments as well as outdoor environments.

- The evaluation process is multifaceted: As the process is important in preschool education, the process needs to be evaluated in many ways.

\subsection{The Aim of the Study}

Teacher characteristics are one of the most important factors affecting the growth of children (MoNE, 2013). Teachers therefore have important responsibilities in the development of early childhood and they should provide children with opportunities to express themselves, to reveal and develop their talents. Vratulis, Clarke, Hoban, and Erickson (2011) found that it was not enough to encourage prospective teachers to use all the opportunities of such technologies in schools by using digitally oriented alternative strategies that they learned in teacher training programs. From this point of view, they stated that teacher education should be realized through explicit modelling and an active reflection and discussion process. In the present study, the Slowmation process was introduced to the pre-school teacher candidates to create short movies about science concepts. The purpose of using the Slowmation technique with pre-service teachers in this way was not to develop their conceptual understanding of science, but to offer them an experience that they could apply during teaching practices with young children. This study is guided by the research questions below:

1) What are the teacher candidates' opinions about the factors that should be considered in the process of preparing a Slowmation?

2) What are the teacher candidates' opinions about the advantages and limitations of the Slowmation technique followed by practice with young children?

\section{Method}

This qualitative study was phenomenological research that focuses on identifying the different ideas and experiences of participants in common practice (Richardson, 1999). There is an increasing interest in understanding the nature of the information experience of people. Since phenomenology highly relates to the attempt of understanding the nature of such experience, it may seem like a suitable research method to be used in this study (Yates, Partridge, \& Bruce, 2012).

\subsection{Participant (Subject) Characteristics}

The participants of the study were 65 sophomores (46 in day-time lessons and 19 in evening-time lessons) from pre-school teacher education program in a state university during the 2017-2018 spring semester. All of the participants were female students. The mean age of the evening group was 21.0 and the mean age of the day group was 21.45 .

Within the scope of the elective course, pre-school teacher candidates who were studying in the fourth semester of undergraduate education took part in the study. The teacher candidates took a total of two compulsory courses, one in the first semester and the other in the second semester. One of them is a course called 'human anatomy and physiology' which is aimed at basic information about the human biological structure. The other is a course called 'mother-child health and first aid' which is aimed at health and emergency intervention. Furthermore, within the scope of elective courses, in the third semester, there is a course called 'mother-child nutrition' which is a course about healthy life. This research was made within the scope of an elective course titled 'Slowmation technique in the pre-school period' in the fourth semester.

\subsection{Sampling Procedures}

The number of participants in the phenomenological studies might vary. In some studies, while sample sizes include three to 10 participants were recommended, in some others it should not be less than 60 and no more than 150 (Flynn \& Korcuska, 2018). Pre-school teacher candidates (from now on, they will be called as teacher candidates) voluntarily participated in the elective course and the study. In the context of this study, teacher 
candidates applied the Slowmation technique with younger children (neighbours, relatives or any kind of proximity that could be easily reached). The majority of the children who participated in the practice were in the pre-school age group but there were also children at the primary school age. The pre-school teacher candidates got the necessary permissions from the families of the children to take part in the study. Therefore, both groups of the participants (teacher candidates and young children) were included in the study using a convenience sampling method. Teacher candidates the day- and evening-time classes were grouped; each group consisted of one, two or four candidates. In this way, there were 17 groups in the day class and 8 in the evening class. The participants did not have any knowledge about the Slowmation technique and science teaching experience before.

\subsection{Slowmation Training Program}

The course lasted 14 weeks and was carried out in four stages. In the first stage, the candidates were divided into groups and each group studied the science-related objectives in the pre-school education program. Science topics were determined according to the science-related objectives in the pre-school program and each group chose one of the related subjects (the topics are same to the list given in Table 1). In order to improve their content knowledge about the science subject, the groups studied from various sources and prepared presentations to their classmates in the classroom environment. After each presentation, the lecturer and the entire class discussed the convenience of the subject to the young children's cognitive and affective characteristics.

In the second stage, the Slowmation technique was taught by the instructor. In this context, the Slowmation preparation and application techniques were given. Various examples of Slowmation found on the Internet were watched in the classroom and their assessments were made together with the teacher candidates in terms of their technical and child level suitability.

In the third stage, teacher candidates prepared their own Slowmations about the science topic they chose. Each group added the scripts and stories to the animations that they thought were appropriate to the young children's level of understanding. They presented their Slowmations to their classmates. The instructor gave feedback on Slowmations by considering criteria such as image and sound quality, the relevance of stories, etc. Also, what should be taken into consideration during the applications with young children was emphasized by the intructor.

In the final stage, the Slowmations were redesigned and participants took part in the process. The teacher candidates asked the children some questions about the subject to define the children's previous knowledge and to draw attention to the relevant science subject. They then asked the children to create the relevant design, stating the materials they used in their slowdown. Teacher candidates explained to children how to take photos and supported children throughout the whole process. Similarly, children were asked questions after the application. The effect of slowmations on children was observed comparatively by prospective teachers. In this course, slowdowns suitable for preschool level are prepared for many different science subjects. Table 1 provides information on the slowdowns prepared by each group and its implementation with children.

Table 1. Science topics of Slowmation by teacher candidates and the number of children

\begin{tabular}{lllll}
\hline Group & $\begin{array}{l}\text { Number of the participant } \\
\text { in the group }\end{array}$ & The subject of science on Slowmation & $\begin{array}{l}\text { Number of } \\
\text { children }\end{array}$ & $\begin{array}{l}\text { Age of } \\
\text { children }\end{array}$ \\
\hline DC1 & 3 & Natural disasters & 1 & 5 \\
DC2 & 4 & Germination & 1 & 9 \\
DC3 & 3 & States of matter & 2 & $5-6$ \\
DC4 & 4 & Digestive system & 9 & 5 \\
DC5 & 3 & Metamorphosis of the butterfly & 1 & 8 \\
DC6 & 3 & Baby's growth in the uterus & 1 & 8 \\
DC7 & 4 & Healthy eating & 1 & 7 \\
DC8 & 4 & Water cycle & 2 & 7 \\
DC9 & 2 & Chick formation from the hatch & 1 & 4 \\
DC10 & 3 & Respiratory system & 1 & 5 \\
DC11 & 3 & Day and night formation & 1 & 5 \\
DC12 & 1 & Acids and bases & 1 & 8 \\
DC13 & 1 & Stars and planets & 1 & 7 \\
DC14 & 3 & Seasons & 1 & 5 \\
DC15 & 2 & Regeneration & 1 & 6 \\
DC16 & 3 & Fermentation of yogurt & 1 & 8 \\
DC17 & 1 & Wind formation & 1 & 5 \\
\hline
\end{tabular}




\begin{tabular}{lllll}
\hline EC1 & 2 & Human developmental periods & 3 & $5,6,8$ \\
EC2 & 3 & Germination & 4 & $4-6$ \\
EC3 & 2 & Solar eclipse & 1 & 7 \\
EC4 & 2 & Lunar eclipse & 1 & 5 \\
EC5 & 3 & Metamorphosis of the butterfly & 10 & 5 \\
EC6 & 3 & Water cycle & 1 & 8 \\
EC7 & 2 & Rain formation & 1 & 7 \\
EC8 & 2 & Density- swimming and sinking & 4 & $4-6$ \\
\hline
\end{tabular}

Note. DC (Day-time Class), EC (Evening-time Class).

In the study, it is known that only 5 groups of children in the preschool age group who participated in the application attend a preschool education institution. Furthermore, the data was unavailable as to whether children in the other pre-school age groups attend any educational institution except those who attend an elementary school.

All groups performed their applications using the five-stage technique proposed by Hoban and Nielsen (2010). Table 2 presents these steps and an example of an application according to each step.

Table 2. Slowmation design process

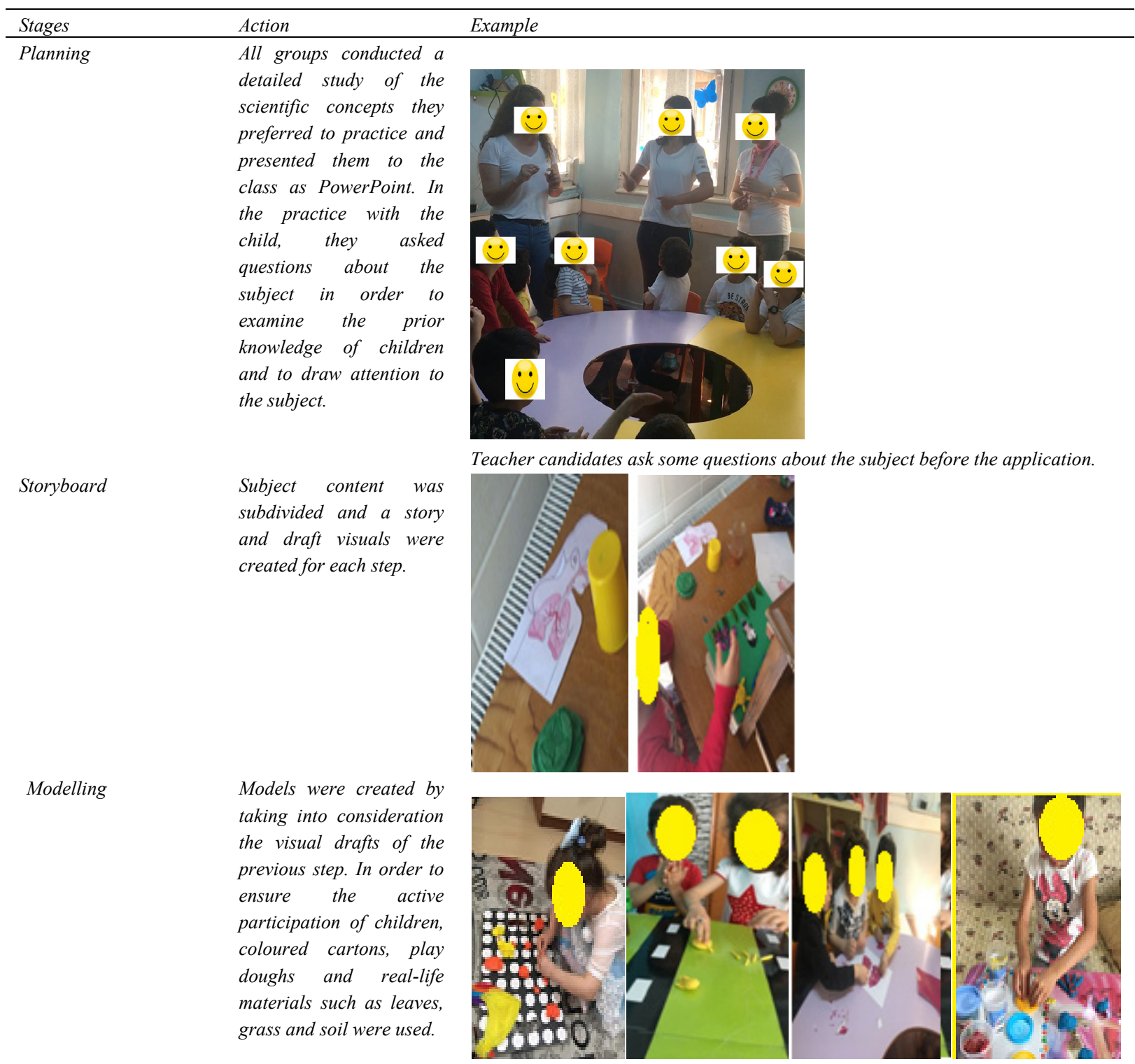




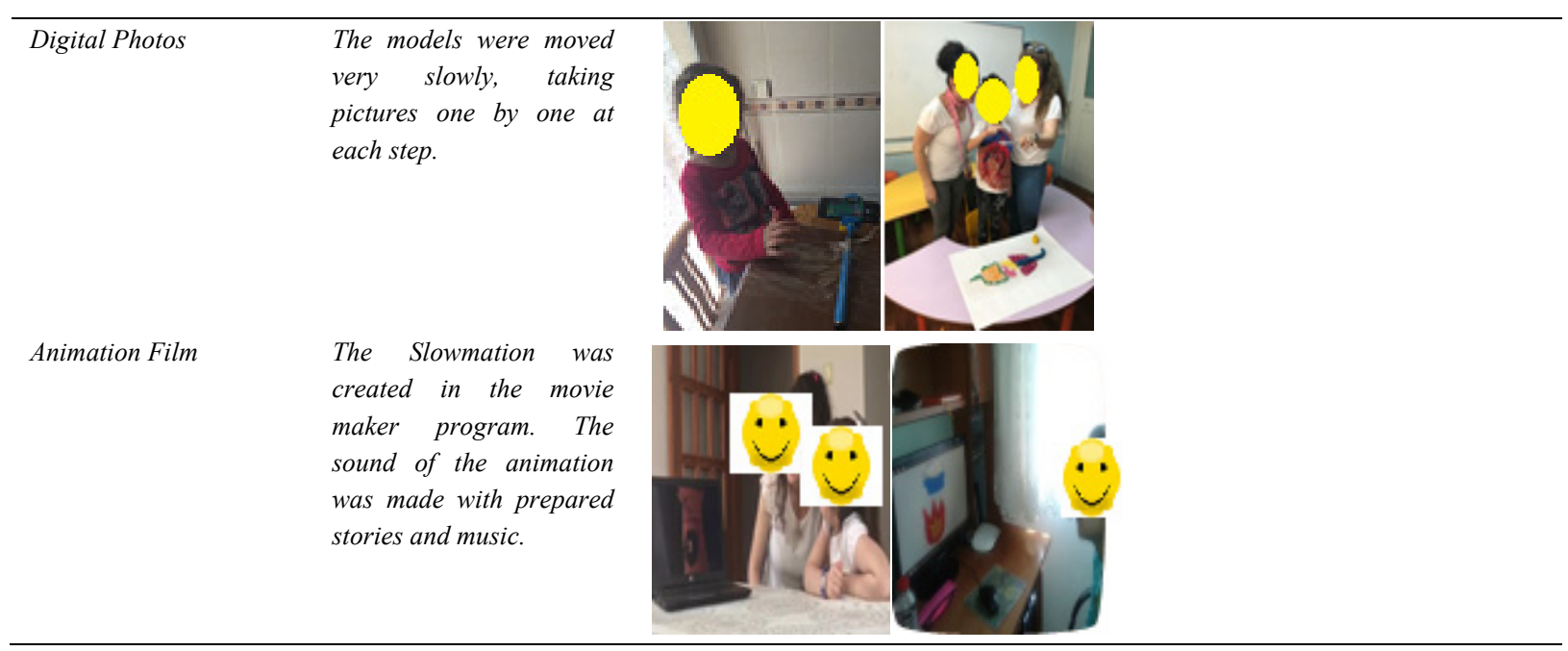

Table 2. Prepared in accordance with the data obtained from the sample.

\subsection{Brief Sample Slowmation}

Germination of seeds: Firstly, detailed research has been done about the scientific concepts that are prominent in the subject. Pre-school teacher candidates asked children some questions about the subject before applying:

Teacher candidate(s): How do plants occur?

Child: We sow the seed in the soil and it grows when we water.

Teacher candidate(s): What are the parts of a plant?

Child: Leaf, flower, root.

Teacher candidate(s): What is the role of the roots of the plant?

Child: The plant drinks water from roots.

Teacher candidate(s): What do you think is germination?

Child: It's the plant to be green.

Teacher candidate(s): What is necessary for germination?

Child: It needs water.

In order to explain the germination of the seed to the child, the story of the tiny bean was prepared. Model and real-life materials such as real soil, the bean from play dough, sun, cloud and rain drawings from coloured cardboard, copper wire for the root were created to fit the story outline. Models were taken with the camera by moving one by one according to the order in the story with children. He first played the models with very large movements and then started to play with small movements. The photographs were uploaded to the animation program by preschool teacher candidates. The voice was performed by the child and the child took the role of the tiny bean in the event. He said the small beans might get cold when it was raining, and the tiny beans would get warm when the sun shines. After the sound is added to the movie, the animation is completed (see Figure 1). After the application, the same questions were redirected to the child as follows:

Teacher candidate(s): How do plants occur?

Child: We plant the seed in the ground. Then it rains and the roots are formed. When the sun comes out, it heats up and the plant grows.

Teacher candidate(s): What are the parts of a plant?

Child: Root, stem, leaf, flower.

Teacher candidate(s): What is the role of the roots of the plant?

Child: Roots are essential for plant nutrition and water intake. It allows the soil to cling to and grow.

Teacher candidate(s): What do you think is germination?

Child: When the seed is planted in the soil it changes into a plant. 
Teacher candidate(s): What is necessary for germination?

Child: It needs rain, sun and soil.
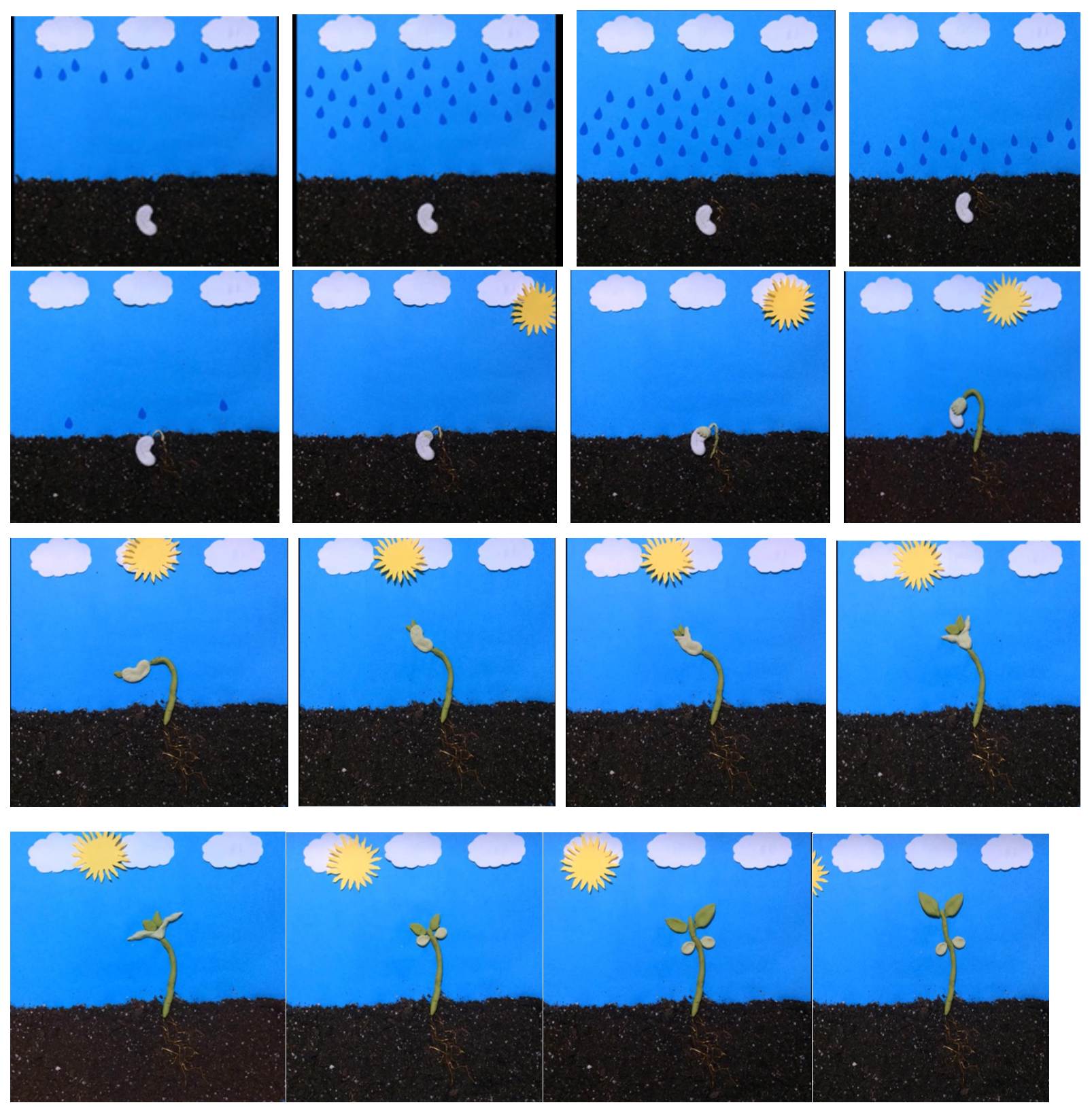

Figure 1. Germination of seed photos recorded from the animation film.

\subsection{Data Collection}

\subsubsection{Observation Notes}

Teacher candidates carefully observed the Slowmation technique during their practice with children. They explained in detail all the situations that the children and themselves encountered in this process. Pre-service teachers prepared and submitted their observations in the form of file sheets.

\subsubsection{Open-Ended Questions}

Open-ended questions were directed to teacher candidates about their opinions on the importance and benefits of Slowmation technique in terms of pre-school science education. Questionnaires directed to prospective teachers in the research are as follows: 
Question 1. State the advantages and limitations of Slowmation technique in terms of science education.

Question 2. Explain the issues to be considered when preparing Slowmations.

Question 3. What is the most important advantage of Slowmation technique? Discuss.

Question 4. Discuss the science issues that are not suitable for using the Slowmation technique in the preschool period.

2.5.3 Animation, Video, Photos and Presentations

Since pre-school teacher candidates should be aware of scientific concepts related to the subject, they conducted detailed research on the subject of science and performed a PowerPoint presentation at the class environment to their classmates and the instructor. They then produced a Slowmation video as a group on the subject they were investigating. Then they created one more Slowmation video on the same subject with the child(ren). Thus, they have developed a total of two Slowmation videos. However, one group stated that they did not prepare a Slowmation video due to the limited time in practice with a group of children. Therefore, 49 Slowmations were created in 25 science topics. In addition, the candidates took videos and photos of the process of creating animation.

\subsection{Data Analysis}

In this study, content analysis method was used. Leedy and Ormrod (2001) define this method as "a detailed and systematic examination of the contents of a particular body of materials for the purpose of identifying patterns, themes, or biases" (p. 155). The data were analyzed in four stages: data coding, definition and organization of the themes, regulation of codes and themes, identification and interpretation of findings. Coding was performed on the data obtained. The relevant answers were then categorized and each established a consistent theme. The data were read repeatedly and the terms that were thematically related to the categories were determined.

In this research, common and different aspects of the findings obtained from data sources such as observation notes, open-ended questions, video and photos were compared with data triangulation for internal validity. External validity is provided by quoting directly from the data obtained from the documents. In the study, there is consistency in the whole process from the sources to the interpretation of internal reliability. External reliability was achieved in this study due to the agreement between the results and the data. As Kolbe and Burnet (1991) state that content analysis is particularly sensitive to research bias, the data are coded together by two authors to enhance inter-interpreter reliability. Due to the data triangulation, no separate coding was made. The statements that the researchers disagreed were discussed and the disagreement was resolved.

\section{Findings}

The data obtained from the experiences and opinions of the teacher candidates about the Slowmation are divided into two subtitles.

3.1 Findings Obtained from Preschool Teacher Candidates' Opinions About the Factors That Should Be Considered in the Slowmation Preparation Process

Three main themes emerged from the factors that should be considered in the preparation of a good quality Slowmation; (a) technical aspects, (b) science subject selection, and (c) models and visualization.

\subsubsection{Technical Aspects}

Pre-school teacher candidates (abbreviated as PT below) stated that the position of the camera, light, and the relationship between the story and voice with the photo transitions should be taken into consideration regarding the technical characteristics of the Slowmations. The opinions about the location of the camera, the light and voice setting are as follows:

PT25: The shadow should not appear in the photos. Background of the figures must be in constacting colors. Figures must be on the horizontal axis. Photos should be taken upright from above. We should not pull the outside of the floor while taking the pictures. (position of the camera and light)

PT32: Do not step out of the ground while photographing. The light must be the same in all the photos. (position of the camera and light)

PT23: The angle of light should be adjusted very well. The level of light in each photograph must be the same. (light)

PT39: We have to tell the story according to the flow of pictures, so we must tell the story according to the flow of the event while watching the animation and then add it to the animation. (The harmony of the storytelling and 
the photos)

PT43: When adding audio and storytelling to the video, the situation of the voice and the photos should be at the same time. (The harmony of the storytelling and the voice)

PT57: The audio transitions should be compatible with the story. (voice)

The teacher candidates emphasized that the camera should be fixed in the photo shoot, that there are no other images in the photographs except the floor where the models are located and that the angle of the light does not change and there should be integrity between the voices and the events in the film.

\subsubsection{Science Subject Selection and the Language of the Story}

The opinions expressed on the topic selection and the language of the story are as follows: The teacher candidates stated that the choice of subject and the language of the story should be appropriate to the student level.

PT2: The subject should be appropriate for the age of the child and should be explained simply. If I take my own example of what I do, it can be given to children by at least one feature, by simplifying, even though many issues are difficult. However, it would be good to choose simpler subjects such as the characteristics of creatures, seasons or sensory organs that are suitable for the pre-school period. Advanced physics topics need not be given to subjects that are difficult to concretize, which exceed the level of the child. Any subject can be explained except the highly abstract concepts and which requires prior knowledge. (Appropriateness to the children level)

PT14: When preparing a Slowmation, firstly a suitable topic should be chosen for science education and children. Subjects may be those that the child need to learn in the preschool period. For example; it may not be appropriate to try to explain the 'reproduction' issue of science subjects for preschool children. (Appropriateness to the children level)

PT33: The story must be told in a fluent language and in a way that children understand. (The language of the story)

The preschool teacher candidates stated that the subject to be explained by using the Slowmation technique should be suitable for the cognitive development characteristics of preschool children and the language used in storytelling should be as simple as children can understand.

\subsubsection{Models and Visualization}

The teacher candidates stated that the size and colours of the models should be like in real life and prepared models should be from the child's immediate familiar environment. Besides, the teacher candidates emphasized that the dimensions of the models should be proportional measurements reflecting the actual dimensions. The opinions regarding the preparation of the models and visualization are as follows:

PT2: Materials should be selected from those used in a child's life such as dough, cardboard, paper, toys, etc. (Familiarity)

PT32: Prepared models and their colours should be appropriate for real life. So, if the Sun and the Earth model are being made, the Sun must be bigger than the Earth. Sun model should be yellow and the earth should be blue. (Colors and sizes should be like in real life.)

PT45: True to life colours must be used. It should be reduced to close to reality. (the tree should not be the same size as the insect.) (Colors and sizes should be like in real life.)

PT51: Shapes should be marked, sizes should be appropriate. Play dough and clay can be used. (Appropriateness)

The teacher candidates also indicated that different colours should be used to distinguish between the background and the model. In the film, which was prepared by using the Slowmation technique, it was emphasized that the situation described in the story and transitions photo should be compatible with each other.

\subsection{Findings Relating to the Pre-School Teacher Candidates' Opinions on the Advantages and Limitations of the} Slowmation Technique

\subsubsection{Advantages of Slowmation Applications on Young Children}

Qualitative data from the open-ended questions were analysed using a content analysis method. The vast majority of pre-service teachers have specified more than one opinion. Within those responses, 135 statements were identified about the advantages of the Slowmation technique. Each student's answers were read several times until all statements had been assigned to one of the following categories of data generated as a result of 
analysis; (a) interest, (b) teamwork/collaborative learning, (c) concentration/visualization, (d) active participation, (e) permanent information/easy learning, (f) skill development, (g) self-confidence, and (h) motivation

Table 3 presents the categories, sub-categories and illustrative quotes relating the advantages of the Slowmation technique on children.

Table 3. Pre-service preschool teachers' opinions about the advantages of the Slowmation

\begin{tabular}{|c|c|c|c|c|c|c|}
\hline Category & $\mathrm{F}$ & $\%$ & Sub-Category & $\mathrm{F}$ & $\&$ & Illustrative quote \\
\hline \multirow[t]{4}{*}{ Interest } & 40 & 29.63 & Attractive & 14 & 10.37 & $\begin{array}{l}\text { A method that can attract children's attention. } \\
\text { Teaches by entertaining }\end{array}$ \\
\hline & & & Curiosity & 10 & 7.41 & \\
\hline & & & Entertaining & 10 & 7.41 & \\
\hline & & & Motivation & 6 & 4.44 & $\begin{array}{l}\text { With this technique, the learning process of the } \\
\text { student, which is irrelevant to the subject or the } \\
\text { lesson, is easier. }\end{array}$ \\
\hline $\begin{array}{l}\text { Teamwork/ } \\
\text { collaborative } \\
\text { learning }\end{array}$ & 23 & 17.04 & & & & $\begin{array}{l}\text { This method strengthens group work and } \\
\text { cooperation }\end{array}$ \\
\hline Concretization/ visualization & 18 & 13.33 & & & & $\begin{array}{l}\text { It is easy to understand because it is visual and } \\
\text { concrete. }\end{array}$ \\
\hline Active participation & 17 & 12.59 & & & & It ensures the active participation of children. \\
\hline Permanent knowledge/learning & 17 & 12.59 & & & & $\begin{array}{l}\text { Supports children's learning and provides } \\
\text { permanent learning. }\end{array}$ \\
\hline \multirow[t]{3}{*}{ Skill development } & 13 & 9.63 & Leadership & 7 & 5.19 & Leadership ability is gained. \\
\hline & & & Creativity & 5 & 3.70 & $\begin{array}{l}\text { Slowmation is an effective method to develop the } \\
\text { creativity of children. }\end{array}$ \\
\hline & 7 & 5.19 & Technology using & 1 & 0.74 & $\begin{array}{l}\text { A product reveals using the technology } \\
\text { Develops self-confidence }\end{array}$ \\
\hline
\end{tabular}

The most common answer to the open-ended question was interest ( $\mathrm{f}=40 ; 29.63 \%$ ). This was followed by teamwork $(\mathrm{f}=23 ; 17.04 \%)$, concretization $(\mathrm{f}=18 ; 13.33 \%)$, active participation $(\mathrm{f}=17 ; 12.59 \%)$, permanent knowledge $(f=17 ; 12.59 \%)$, skill development $(f=13 ; 9.63 \%)$, and self-confidence $(f=7 ; 5.19 \%)$.

The illustrative quotes regarding each category and sub-categories related to the advantages of the Slowmation technique are as follows:

Interest

The most common category was interest $(f=40 ; 29.63 \%)$. Attractive $(f=14 ; 10.37 \%)$, curiosity $(f=10 ; 7.41 \%)$ entertainment $(f=10 ; 7.41 \%)$ and motivation $(f=6 ; 4.44 \%)$ sub-categories took place in this category. Illustrative quotes for subcategories are shown below.

PT38: Children can learn with this technique in a fun way (Entertaining)

PT25: The most important advantage is that it teaches the concept of science with fun and cooperation (Entertainment \&cooperation).

PT8: With this technique, the learning process of the student who is irrelevant to the subject or the course is easier. It is interesting because it increases the relevance of the lesson (Attractive).

PT46: Explained children's curiosity and contributed to their cognitive and emotional development. It was fun learning. (Curiosity\&Entertainment)

PT3: This study has played a major role in the emergence of children's interest and curiosity. (Entertainment \&curiosity)

PT52: I have observed that it increases motivation in students. (Motivation)

Teamwork/Collaborative learning

The second highest specified category was teamwork/collaborative learning ( $f=23 ; 17.04 \%$ ) about the advantages of the Slowmation technique. Sample opinions are given below.

PT2: Working within the group, the child experiences the spirit of being a team and the happiness of working. Learn to help and share 
PT8: Learn to do the division of labour and to work together.

PT27: Develops group work and leadership characteristics.

\section{Concretization/visualization}

Some of the pre-service pre-school teachers mentioned that the most important advantage of the Slowmation technique is the concretization and visualization of abstract issues $(\mathrm{f}=18 ; 13.33 \%)$.

The following comments were typical responses with respect to this category:

PT38: It makes it easier for children to tell us about progressive events related to science. Because it is not possible to see all stages of frog formation in real life (visualization)

PT43: It may be that the child can show science subjects in stages.

PT12: The most important advantage I think is that the film is crafted on the ground with photos taken by simply changing small details. Supporting visual learning in this way rather than just a photograph is the most important advantage of the Slowmation technique.

PT46: This activity contributed greatly to children's understanding of abstract issues. Active participation

A few of the teacher candidates ( $\mathrm{f}=17 ; 12.59 \%$ ) stated that active participation is one of the advantages of the Slowmation technique. An example quote is shown below.

PT53: The most important advantage is that children can actively participate in each stage. It provides learning by doing.

\section{Permanent knowledge/learning}

Similarly, $12.59 \%$ of the teacher candidates mentioned that learning and permanent knowledge relating to the advantages of the Slowmation technique. Pre-service science teachers' common views in this category were as follows:

PT2: The child learns to do this and makes it easier and more permanently.

PT22: This activity was very useful for children's learning. They touched the bodies made of play dough in a concrete way and carried out the breakdown of the food and the stages themselves.

Skill development

Pre-service science teachers (9.63\%) suggested that skill development could be one of the advantages of the Slowmation technique. Among these skills, leadership (5.19\%), creativity (3.70\%) and technology using (.74\%) are prominent. The following comments were typical responses with respect to this sub-themes:

PT2: Modeling, story writing parts improve the creativity of the child. So that makes him/her think about research about a science topic (creativity)

PT2: The child creates a product using technology (technology using).

PT26: Improves the leadership characteristic of the child (leadership).

Self-confidence

A number of students (5.19\%) stated that self-confidence is one of the advantages of the Slowmation technique. One of the students said:

PT10: Because of what he is doing, his sense of accomplishment increases and he is happy to be able to fulfil his responsibilities. Self-confidence increases because he finds himself in the incident.

3.3 Pre-Service Preschool Teachers' Opinions about the Limitations of the Slowmation Technique.

Overall, 106 statements were identified within the responses about the limitations of the Slowmation technique. Each student's answers were read several times until all statements had been assigned to one of the following categories; (a) time-consuming/challenging, (b) Challenging, (c) cost-effective, (d) material choice, (e) class management, (f) topic choice, $(\mathrm{g})$ group disputes, $(\mathrm{h})$ timid students

The limitations of the Slowmation technique specified by the pre-service preschool teachers are seen in Table 4. 
Table 4. Pre-service preschool teachers' opinions about limitations the Slowmation technique

\begin{tabular}{|c|c|c|c|}
\hline Category & $\mathrm{f}$ & $\%$ & Illustrative quote \\
\hline Time-consuming & 49 & 46.23 & $\begin{array}{l}\text { The limitations are that it is time-consuming and it needs a lot of preparing in every stage. } \\
\text { (PT48) }\end{array}$ \\
\hline Challenging & 16 & 15.09 & A difficult activity to happen without help. (PT2) \\
\hline Cost-effective & 11 & 10.38 & Sometimes it can be costly. (PT62) \\
\hline Material selection & 11 & 10.38 & A waiting period is necessary for some materials such as clay. (PT16) \\
\hline Class management & 7 & 6.60 & Problems can be experienced in the application phase in crowded classes. (PT50) \\
\hline Subject selection & 6 & 5.66 & It is difficult to describe in the stages selection of the wrong topic. (PT33) \\
\hline Intra-group disputes & 4 & 3.77 & It may cause disputes regarding cooperation. (PT8) \\
\hline Timid students & 2 & 1.89 & $\begin{array}{l}\text { It can be constituted the problem self-confidence for children. They may not feel } \\
\text { comfortable. (PT42) }\end{array}$ \\
\hline
\end{tabular}

Note. $*$ The vast majority of pre-service teachers have specified more than one view.

Most of the learners ( $\mathrm{f}=49,46.23 \%$ ) indicated that the time consuming and preparation challenging features are the most important limitations of the Slowmation technique. These features were followed by the opinions that it is challenging ( $f=16,15.09 \%$ ), cost-effective ( $f=11,10.38 \%$ ), material selection ( $f=11,10.38 \%$ ), class management $(f=7,6.60 \%)$, subject selection ( $f=6,5.66 \%$ ), intra-group disputes $(f=4,3.77 \%)$, and timid students $(\mathrm{f}=2,1.89 \%)$. Student responses are coded to comply with some of these categories as follows:

PT2: But it is time-consuming, challenging and difficult to accomplish without help (Time-consuming, challenging).

PT38: As a limitation, can be exhausting and difficult to do in a crowded class environment. The teacher may not be able to maintain the order and control of the class while performing the activity. Each child may not exercise equally. The child who cannot apply may regret this time. (Class management, challenging)

PT8: In case of preparation in a class environment, the use of materials and the construction of the fiction may be problematic. It takes a long time to terminate because it requires more processing. It can cause conflicts as it requires working with cooperation (challenging, intra-group disputes)

PT27: The limitations are that the time-consuming and construction stages are a little more difficult. Not always applicable (challenging)

PT62: Sometimes it may be costly. Shooting may take time. (cost-effective, time consuming)

PT65: In addition, we must have good facilities such as very high technology. This is also expensive (cost-effective)

PT16: It may be difficult to choose the subject appropriate to the level of children. We should also choose materials that are durable and do not deteriorate quickly (subject and material selection).

\section{Results and Discussion}

In this study, it was aimed to evaluate the pre-school teacher candidates' opinions about the preparation and implementation of an activity covering all stages of the Slowmation process in science education. This study also focused on the pre-school teacher candidates' teaching experiences by using a Slowmation to teach scientific concepts to young children. The results of the study were summarized in two categories according to the findings obtained from the development and implementation experiences of teacher candidates: (a) characteristics of a good Slowmation and (b) advantages and limitations of the Slowmation.

The thoughts expressed by the pre-school teacher about the issues to be taken into consideration in the process of slowmotion animation are one of the important results through the data triangulation. Teacher candidates emphasized that technical aspects, selection of science subjects, models and visualization were very important in the process of preparing a Slowmation. These are the features that should be in a good Slowmation.

Relating the technical aspects, the position of the camera and the light on the ground should be constant. Accordingly, a high-quality animation video should be shot from a fixed point so that the photos are not shadowed. This ensures that the light comes at the same angle to all pictures. To ensure that the light comes from a fixed point that corresponds to all photographs provides technically clearer image. In addition, the Slowmations used should be slow and clear enough to perceive movements, changes and their timing, and to understand the relationship between the chapters and the sequence of events (Hoban et al., 2011).

One of the points to be considered in the process of preparing a Slowmation was the choice of subject. In this 
study, it was emphasized that the science subject should be appropriate to the development and age levels of pre-school children. It is concluded that preschool children will have difficulty in understanding the subjects that cannot be divided into phases, which are not in a loop, even if they are supported by concrete materials with the subjects that are not encountered in daily life. As a matter of fact, issues such as atom, force, pressure, density, volume, space concepts, reproduction, cell divisions, photosynthesis, acid-base and chemical reactions are difficult to understand for pre-school children. In this study, the preparation of a Slowmation related to some of these issues supports this interpretation. However, this result does not mean that Slowmations cannot be prepared in related subjects. These issues are not only relevant to the cognitive development characteristics of pre-school children. Keast and Cooper (2011) stated that the experience of pre-service teachers suggests that the Slowmation films are most effective when the chosen concept is small, self-sufficient, easy to fragment and represent.

The other important issue was the models and visualization of the preparation process of preparing a Slowmation. The model should be easily distinguishable from the stationary floor. For this, different colours should be used in the model and background. The results of the models were similar to the proportions of the real size. Otherwise, the model will not reflect reality. Preschool children have not reached the maturity to be able to focus on the details and small objects developmentally (Yeşilyaprak, 2011). A wide variety of materials such as doughs and cardboards can be used as well as natural materials such as fruits, stones and leaves in the models (Hoban, 2007; Hoban, 2010; Hoban \& Nielsen, 2010; Hoban et al., 2011).

With the second research question, some advantages and limitations related to the Slowmation have been determined through the experiences of teacher candidates with young children in this process. The most important advantage of preparing Slowmation applications for children is that interest dimension of slowmations which is similar to the findings of Hoban et al. (2009). Preperation process of slowmations has attracted the attention of children, especially as it is technically similar to a cartoon creation process. This was followed by collaboration/teamwork, concretization/visualization, active participation, permanent learning, skill development and self-confidence. Emphasizing the abstract science concepts of the Slowmation technique was in accordance with many studies in the literature (Fleer \& Hoban, 2013; Kervin, 2007). It also provided meaningful and permanent learning by visually and slowly explaining an event in detail. The active participation was provided by cooperation within the group in the lesson so communication, self-confidence, leadership, and assistance skills are developed and provided effective learning in an entertaining environment.

In the research, despite many advantages, some limitations were also observed. An activity that is performed using a Slowmation requires more time, it is among the leading limitations (Ekici \& Ekici, 2011). In addition, sometimes it may be a difficult activity to apply in crowded classes because the teacher can encounter some problems in classroom management (Uzun \& Karaman, 2015). Also, a number of disagreements can be observed because group work is required. The teacher cannot be focused on providing class control here again. Because of active participation, it may be difficult to add each student to the event. Besides, there were also some thoughts, concluded from the results, that cannot be applied to every science subject. Most teacher candidates expressed that they will apply the Slowmation technique in the science lessons when they start teaching. Only one teacher candidate stated she did not intend to apply the Slowmation technique in science lessons because the practice was very time consuming and challenging.

In order to gain a successful Slowmation experience, teacher candidates should not only develop practical skills but also be aware of the advantages and limitations during the process with young children. Therefore, the phenomenological study focused on the characteristics of a good Slowmation in the preschool period and the limitations and advantages of the method, based on the experience of Slowmation development and application with children. Specifically, involving young children in making a Slowmation with pre-service teachers ensures a context for supporting concept structuring (Fleer \& Hoban, 2012).

It is not very common for teacher candidates to create animations to explain science concepts in science teacher education (Hoban \& Nielsen, 2014). The Slowmation technique may require a long preparation process. Consequently, it could be a challenge if it is not planned with scrutiny. Furthermore, time challenges can be exceeded as well as using additional cameras or smaller groups (Kervin, 2007). However, the result of this study was that due to the simplicity of the Slowmation technique, teacher candidates could learn how to create Slowmation in a very short time and then improve them in their own environment. Some teacher candidates suggested that Slowmation technique may be more appropriate for primary level compared to pre-school because they think providing class wholeness will be difficult in the preschool period. Some teacher candidates thought that children should not be involved in Slowmation preparation, but that only a pre-prepared study should be made available to children. But in this case, many of the gains related to Slowmation may not be reached. It is 
important that all stages of Slowmation are experienced by the children. Brown et al. (2013) stated that student participation in construction a Slowmation gave students the opportunity to create multiple representations of basic science concepts. A teacher candidate stated that she was concerned to maintain control of the crowded class during the practice. However, if she could get support from other teachers or parents, she definitely wanted to implement the practices. This result can translate to advantage many limitations related to Slowmation. For example, in this way it can be much easier to provide class management in crowded classes. In addition, there is more than one teacher in the class to facilitate class management in the Slowmation application. Only the teacher candidate stated that did not think of the Slowmation, because, requires much time of the Slowmation, and after a while, children will lose attention during the application. However, this situation can be prevented by selecting a topic fully suitable for preschool children's level.

Teachers are required to design activities considering the objectives mentioned in the program. Activities in science education enable pre-school students to develop a positive attitude towards science. Learning centers, each of which covers a different development area are necessary for pre-school students, where they can move freely and have a good time. Science centers are important areas that support child development. A learning center encourages children to develop a desire to learn and to learn new things by discovering the world they live in (MoNE, 2013). Slowmation app is an activity aimed at the requirements pre-school education program. This activity includes objectives that will support the field-specific developmental characteristics of the children.

With pre-school education, children gain early life experiences. Early life experiences determine the attitudes of the child towards school, learning and developing skills that exist in them (MoNE, 2013). The quality of education provided in the preschool period is a major factor in determining the degree of these attitudes. Here, the family environment is also emphasized as the most important factor in the development of the child from the first years to preschool education. Because not all children attend an educational institution in the pre-school period. Family affects the child's development in many aspects, both mentally and physically. Accordingly, children develop positive or negative attitudes as a result of the education they receive in an educational institution or family environment in the preschool period. In this research, it was seen that the creative thinking skills of children who received pre-school education improved more than children without pre-school education (Yaşar \& Aral, 2010).

The play-based activities have a very important place in preschool education (MoNE, 2013). Slowmation preparation process can meet the needs of children to play. Therefore, the Slowmation technique can also be evaluated within structured game events. Structured plays are activities whose rules are determined by someone else to support the developmental progress of children (MoNE, 2013). However, it is the teachers who sets the rules in the Slowmation activity which is a completely different activity from traditional children's games in this category of games. Children play a scientific game with their peers in a fun way in this slowmation process within the gains and indicators. Thus, slowmation applications consistent with the basic characteristics of the preschool education program. However, there are no statements that are parallel to this situation among the data obtained from preschool teacher candidates. The reason for this is that the teacher candidates did not take game-themed courses within the scope of elective courses until the period of their education. In this context, it is very important for teacher candidates to integrate pre-school children's characteristics and instructional technology courses as well as science courses in order to achieve successful slowmation practices.

As a result, teacher candidates gained experience in Slowmation technique and realized the advantages and limitations that will affect their future applications. Thus, after this training, pre-service pre-school teachers can create the Slowmation alone which they can use as a teaching resource in their own lessons when they become teachers in the future.

\section{References}

Brown, J., Murcia, K., \& Hackling, M. (2013). Slowmation: A multimodal strategy for engaging children with primary science. Teaching Science, 59(4), 14-20.

Ekici, E., \& Ekici, F. (2011). A new and effective way of benefiting from information technology in science education: Slowmations. Elementary Education Online, 10(2), 1-9.

Fleer, M., \& Hoban, G. (2012). Using 'Slowmation' for intentional teaching in early childhood centres: Possibilities and imaginings. Australasian Journal of Early Childhood, 37(3), 61-70. https://doi.org/10.1177/183693911203700309

Flynn, S. V., \& Korcuska, S. J. (2018). Credible phenomenological research: A mixed - methods study. Counselor Education \& Supervision, 57, 34-50. https://doi.org/10.1002/ceas.12092 
Hoban, G. (2005). From claymation to Slowmation: A teaching procedure to develop students' science understandings. Teaching Science: Australian Science Teachers' Journal, 51(2), 26-30.

Hoban, G. (2007). Using Slowmation to engage preservice elementary teachers in understanding science content knowledge. Contemporary Issues in Technology and Teacher Education, 7(2), 1-9.

Hoban, G. (2009). Facilitating learner-generated animations with Slowmation. In L. Lockyer, S. Bennett, S. Agostino \& B. Harper (Eds.), Handbook of research on learning design and learning objects: Issues, applications, and technologies (pp. 313-330). Hershey, PA: IGI Global. https://doi.org/10.4018/978-1-59904-861-1.ch015

Hoban, G., Loughran, J., \& Nielsen, W. (2011). Slowmation: Preservice elementary teachers representing science knowledge through creating multimodal digital animations. Journal of Research in Science Teaching, 48(9), 985-1009. https://doi.org/10.1002/tea.20436

Hoban, G. F., Macdonald, D. C., Ferry, B., \& Hoban, S. (2009). Simplifying animation with "Slowmation" to encourage preservice teachers' science learning and teaching (pp. 2838-2847). EDMEDIA2009 World Conference on Educational Multimedia, Hypermedia and Telecommunications. Cheapasake, VA: Association for the Advancement of Computing in Education.

Hoban, G., \& Nielsen, W. (2010). The 5Rs: A new teaching approach to encourage Slowmations (student-generated animations) of science concepts. Teaching Science, 56(3), 33-38.

Hoban, G. \& Nielsen, W. (2012). Using "Slowmation" to enable preservice primary teachers to create multimodal representations of science concepts. Research in Science Education, 42, 1101-1119. https://doi.org/10.1007/s11165-011-9236-3

Hoban, G., \& Nielsen, W. (2013). Learning Science through Creating a 'Slowmation': A case study of preservice primary teachers. International Journal of Science Education, 35(1), 119-146. https://doi.org/10.1080/09500693.2012.670286

Hoban, G., \& Nielsen, W. (2014). Creating a narrated stop-motion animation to explain science: The affordances of "Slowmation" for generating discussion. Teaching and Teacher Education, 42, 68-78. https://doi.org/10.1016/j.tate.2014.04.007

Keast, S., Cooper, R., Berry, A., Loughran, J., \& Hoban, G. (2010). Slowmation as a pedagogical scaffold for improving science teaching and learning. Brunei International Journal of Science and Mathematics Education, 2(1), 1-15.

Keast, S., \& Cooper, R. (2011). Developing the knowledge base of preservice science teachers: Starting the path towards expertise using Slowmation. In D. Corrigan, J. Dillon \& R. Gunstone (Eds.), The Professional Knowledge Base of Science Teaching. Springer, Dordrecht. https://doi.org/10.1007/978-90-481-3927-9_15

Kervin, K. (2007). Exploring the use of slow motion animation (Slowmation) as a teaching strategy to develop year 4 students' understandings of equivalent fractions. Contemporary Issues in Technology and Teacher Education, 7(2), 100-106.

Leedy, P., \& Ormrod, J. (2001). Practical research: Planning and design (7th ed.). Upper Saddle River, NJ:Merrill Prentice Hall. Thousand Oaks: SAGE Publications.

Lin, C-H. (2012). Application of a model for the integration of technology in kindergarten: An empirical investigation in Taiwan. Early Childhood Education Journal, 40, 5-17. https://doi.org/10.1007/s10643-011-0494-5

Macdonald, D., \& Hoban, G. (2009). Science content knowledge gained through the use of Slowmation. The International Journal of Learning, 16(6), 319-330. https://doi.org/10.18848/1447-9494/CGP/v16i06/46366

Ministry of National Education (MoNE). (2010). Elementary science and technology course curriculum. Ankara [In Turkish].

Nielsen, W., \& Hoban, G. (2015). Designing a digital teaching resource to explain phases of the moon: A case study of preservice elementary teachers making a Slowmation. Journal of Research in Science Teaching, 52(9), 1207-1233. https://doi.org/10.1002/tea.21242

Paige, K., Bentley, B., \& Dobson, S. (2016). Slowmation: an innovative twenty-first-century teaching and learning tool for science and mathematics pre-service teachers. Australian Journal of Teacher Education, 4l(2), 1-15. https://doi.org/10.14221/ajte.2016v41n2.1 
Richardson, J. T. E. (1999). The concepts and methods of phenomenographic research. Review of Educational Research, 69(1), 53-82. https://doi.org/10.3102/00346543069001053

Uzun, E., \& Karaman, İ. (2015). Modeling and student views of the photoelectric event with slow motion animation technique. KSU Journal of Social Sciences, 12(2), 211-226.

Vratulis, V., Clarke, T., Hoban, G., \& Erickson, G. (2011). Additive and disruptive pedagogies: The use of Slowmation as an example of digital technology implementation. Teaching and Teacher Education, 27, 1179-1188. https://doi.org/10.1016/j.tate.2011.06.004

Yaşar, M., \& Aral, N. (2010). The Effect of Preschool Education on Creative Thinking Skills. Theoretical Education Science, 3(2), 201-209.

Yates, C., Partridge, H., \& Bruce, C. (2012). Exploring information experiences through phenomenography. Library and Information Research, 36(112), 96-119. https://doi.org/10.29173/lirg496

Yeşilyaprak, B. (Ed). (2011). Education Psychology Development-Learning-Teaching. Ankara: Pegem Academy.

\section{Copyrights}

Copyright for this article is retained by the author, with first publication rights granted to the journal.

This is an open-access article distributed under the terms and conditions of the Creative Commons Attribution license (http://creativecommons.org/licenses/by/4.0/). 